\title{
Certolizumab Pegol Treatment in Three Patients With Takayasu Arteritis
}

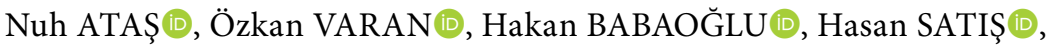 \\ Reyhan BİLICI SALMAN ${ }^{\circ}$, Abdurrahman TUFAN(B)
}

Department of Internal Medicine, Division of Rheumatology, Gazi University Faculty of Medicine, Ankara, Turkey

\begin{abstract}
Although glucocorticoids are the mainstay of treatment in Takayasu arteritis (TA), anti-tumor necrosis factor agents are other treatment options in refractory disease. The onset of TA is generally observed in females of reproductive age. Certolizumab pegol (CZP) lacks a fragment crystallizable region and this gives advantage of minimal transfer through the placenta, which makes CZP a safer option in pregnancy. Although there are case reports and trials about use of infliximab, etanercept, and adalimumab in TA, there are scarce data about use of CZP. In this article, we present three TA cases treated with CZP. While two patients benefited from CZP, one patient was refractory to CZP.

Keywords: Anti-tumor necrosis factor, certolizumab pegol, pregnancy, Takayasu arteritis.
\end{abstract}

Takayasu arteritis (TA) is a rare granulomatous large vessel vasculitis which primarily affects aorta and its major branches. TA can result in stenosis, occlusion, aneurysm formation, and dilatation of effected vessels. ${ }^{1}$ Females are predominantly affected with an age of onset of $\leq 40$ years. ${ }^{2}$ Although its distribution is worldwide, it generally affects Asian populations. TA is relatively uncommon in northern European and American populations. ${ }^{3}$ Although the etiology of TA is unknown, cell-mediated autoimmunity and genetic factors have an important role in the pathogenesis of TA. ${ }^{4}$

Clinical manifestations are determined by the affected vessels and degree of inflammation. ${ }^{5}$ TA generally progresses through three different phases. In the first prevasculitic phase, patients complain of nonspecific constitutional symptoms such as fever, fatigue, and malaise. In the second inflammatory phase, vascular pain (particularly carotidynia) tends to occur. The third burnedout phase is characterized with arterial bruits, decreased or absence of pulses and/or differences in arterial blood pressure between upper extremities, claudication in the legs and ischemic symptoms. ${ }^{6}$ An overlap may be observed between these phases. There is no gold standard laboratory test and imaging method for diagnosis of TA. The American College of Rheumatology (ACR) criteria are the most widely used vasculitis classification criteria. $^{7}$

The main target of treatment in $\mathrm{TA}$ is to suppress the inflammatory process. Management of cardiovascular risk factors such as dyslipidemia, smoking, and hypertension is also important. Corticosteroids (CS) are the mainstay of therapy. Methotrexate (MTX), azathioprine (AZA), cyclosporine, tacrolimus, mycophenolate mofetil,

Received: September 14, 2018 Accepted: January 19, 2019 Published online: March 28, 2019

Correspondence: Nuh Ataş, MD. Gazi Üniversitesi Tıp Fakültesi İç Hastalıkları Anabilim Dalı, Romatoloji Bilim Dalı, 06500 Beşevler, Ankara, Turkey. Tel: +90 312 - 2025828 e-mail: nuh_atas@yahoo.com 
and leflunomide (LEF) are second-line conventional immunosuppressive agents. Conventional agents are used alone or in combination to taper CS dose. Tocilizumab, rituximab, and anti-tumor necrosis factor (anti-TNF) agents are treatment options in refractory cases. ${ }^{6,8,9}$ Angioplasty and stenting may be used to treat stenotic lesions that cause ischemic symptoms. ${ }^{10}$ Although anti-TNF agents are used in treatment of TA, interestingly, there are case reports of TA developing after initiation of these agents in the literature. ${ }^{11-13}$ In these case reports, two patients with spondyloarthritis, one patient with rheumatoid arthritis, and one patient with Crohn's disease developed TA after treatment with anti-TNF agents. This paradoxical effect may be due to the presence of different pathophysiologic pathways in a subgroup of patients with TA.

The currently used anti-TNF-alpha $(\alpha)$ agents in treatment of autoimmune disorders are etanercept (ETA) (TNF- $\alpha$-receptor fusion protein), infliximab (IFX), adalimumab (ADA), golimumab (anti-TNF- $\alpha$ monoclonal antibodies), and certolizumab pegol (CZP). CZP is a PEGylated antigen-binding fragment $\left(\mathrm{F}_{\mathrm{ab}}\right)$ of monoclonal antibody to TNF- $\alpha$. CZP binds and neutralizes soluble and transmembrane TNF- $\alpha$. Unlike other TNF- $\alpha$ inhibitors, CZP lacks a fragment crystallizable $(\mathrm{Fc})$ region. This decreases potential Fc-mediated effects such as complement and antibody dependent cell-mediated cytotoxicity. ${ }^{14}$ In addition, lack of a Fc region gives advantage of minimal transfer through the placenta, which makes CZP a safer option in pregnancy. 15 There are no sufficient data about CZP use in TA in the literature. Therefore, in this study, we aimed to share our experience about CZP use in three patients with a diagnosis of TA.

Diagnosis of patients were in accordance with ACR classification criteria and we used Kerr's criteria (National Institutes of Health) for the evaluation of disease activity in our patients. ${ }^{16}$ According to Kerr's criteria, new onset or worsening of at least two of the following four criteria shows active disease: (i) systemic features such as malaise, weight loss, fever, and arthralgia with no identified cause, (ii) elevated erythrocyte sedimentation rate (ESR), (iii) findings of vascular ischemia or inflammation, like claudication, diminished or absent pulse, (iv) typical angiographic features. The administration dosage of CZP was $400 \mathrm{mg}$ loading dose at weeks 0, 2, 4 and $200 \mathrm{mg}$ in every two weeks thereafter. A written informed consent was obtained from all patients.

A literature review with no date limit was performed for the manuscripts about CZP use in TA. The search was performed in two electronic databases (MEDLINE/PubMed and Scopus) using the following search terms: "Takayasu arteritis", "large vessel vasculitis" and "certolizumab." We included all manuscripts (case reports, search articles, case control, cohort or cross-sectional studies) related with TA and CZP. Exclusion criteria were manuscripts which were not accessible in full-text or publication in languages other than English. After analysis, we found one brief report about $\mathrm{CZP}$ use in $\mathrm{TA} .{ }^{17} \mathrm{We}$ also realized an abstract related with CZP use in TA in 2018 ACR/Association of Rheumatology Health Professionals (ARHP) Annual Meeting. ${ }^{18}$

\section{CASE REPORT}

Case 1- A 42-year-old female patient was operated with bypass graft for left subclavian artery stenosis causing arm claudication in 2009 and subsequently diagnosed of TA with classical angiography consistent with type 2a TA involvement. MTX and $1 \mathrm{mg} / \mathrm{kg}$ methylprednisolone (MP) were prescribed at the beginning of treatment. In follow-up, because of inefficacy, MTX was switched to AZA which caused pancreatitis. Then, AZA was changed to LEF ensuing clinical and laboratory remission for three years. In follow-up, patient developed back pain and control magnetic resonance (MR) angiography revealed progression in stenosis of ascending aorta when compared to previous MR angiography image. After pulse steroid (1 g/day, three consecutive days), IFX treatment was begun. With IFX treatment, back pain and other constitutional symptoms improved. The levels of ESR and C-reactive protein (CRP) decreased to normal range. There was no progression in control MR angiography which was performed at first year of IFX treatment. On second year of IFX treatment, patient developed constitutional symptoms and elevation of ESR and CRP was observed. For this reason, IFX was switched to ETA due to loss of efficacy. Six months later, she admitted to our clinic with abdominal pain, 
weight loss, and bloody diarrhea. Colonoscopy revealed focal ulcerations adjacent to areas of normal appearing mucosa and polypoid mucosal changes that give a cobblestone appearance and diagnosed as Crohn's disease. After diagnosis of Crohn's disease, ETA was switched to CZP and LEF was continued. She was treated with CZP for 26 months and she is still in clinical, laboratory, and angiographic remission for TA. Crohn's disease is also in remission.

Case 2- A 46-year-old female patient was diagnosed of TA in 2010 with complaints of headache, carotidynia, malaise, lassitude, and syncope. There were bruits over carotid arteries and left subclavian artery, absence of left arm pulses, and systolic blood pressure difference between two arms. ESR and CRP levels were 65 (normal: 0-20) $\mathrm{mm} /$ hour and 30 (normal: 0-5) $\mathrm{mg} / \mathrm{L}$, respectively, at initial presentation. Angiographic involvement was consistent with type $2 \mathrm{~b}$ TA. Methylprednisolone $1 \mathrm{mg} / \mathrm{kg}$ day and MTX $15 \mathrm{mg} /$ week were prescribed initially. She was doing well with this treatment for five years but presented with complaints of carotidynia, back pain, and malaise while receiving MTX $15 \mathrm{mg}$ and MP $10 \mathrm{mg} /$ day. Her ESR and CRP levels were $47 \mathrm{~mm} /$ hour and

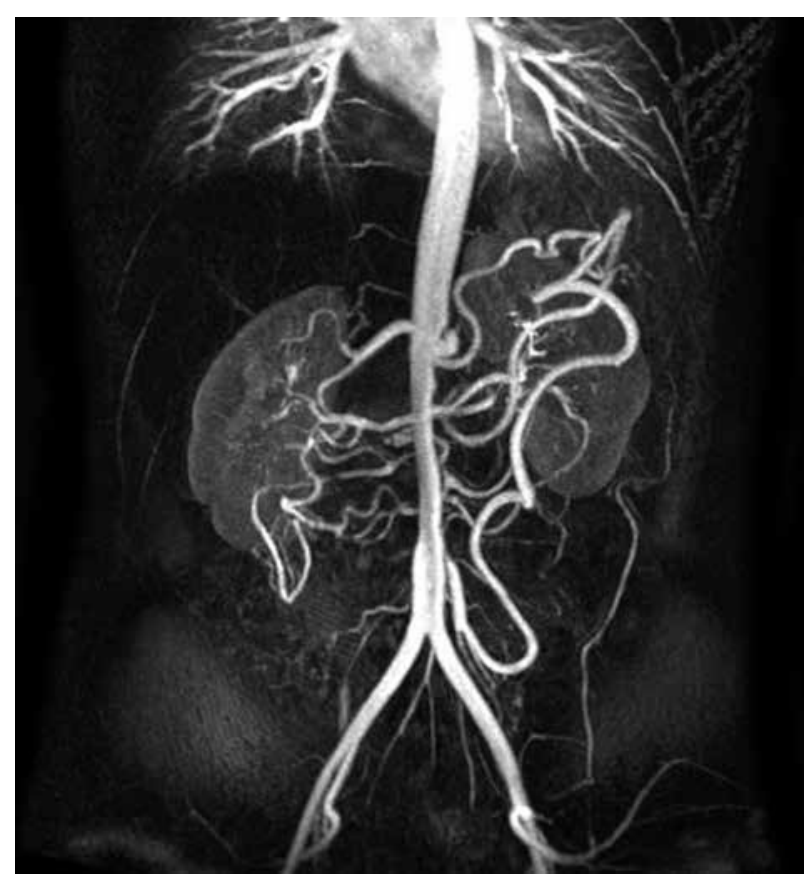

Figure 1. Magnetic resonance angiography demonstrating contrast enhancement and edema of vascular wall in left renal artery.
$26 \mathrm{mg} / \mathrm{L}$, respectively. Patient was prescribed CZP along with MTX. On follow-up visit, after 15 weeks of CZP treatment, she still complained of carotidynia and marked malaise. Her ESR and CRP levels were $42 \mathrm{~mm} /$ hour and $22 \mathrm{mg} / \mathrm{L}$, respectively, and CZP was switched to IFX which was also ineffective with 16 weeks of use. Finally, she achieved remission with tocilizumab treatment.

Case 3- A 33-year-old female patient was diagnosed of TA in 2013 with complaints of malaise, anorexia, systolic blood pressure difference, high ESR (120 mm/hour) and CRP (79 $\mathrm{mg} / \mathrm{L}$ ), and type $\mathrm{V}$ angiographic involvement. MTX and $1 \mathrm{mg} / \mathrm{kg}$ MP were prescribed at the beginning of treatment. Because of gastric intolerance, MTX was changed to LEF. We tapered MP dose gradually. With $15 \mathrm{mg} /$ day dose of MP, we observed elevation of ESR (80/hour) and CRP (58 mg/L) with complaints of weakness, malaise, and fever. On control MR angiography, a new finding, narrowing of left renal artery that involved $8.5 \mathrm{~cm}$ segment with contrast enhancement and edema of vascular wall, was observed. Patient had plans of conception. So, LEF was discontinued and cholestyramine wash-out procedure was initiated and control LEF level was studied. Due to the progression of disease and wish for pregnancy, CZP was initiated. She was treated with CZP for 12 months and MP dose was tapered to $5 \mathrm{mg} /$ day. At one year of CZP treatment, she was still in laboratory (ESR: $26 \mathrm{~mm} /$ hour, CRP: $3 \mathrm{mg} / \mathrm{L}$ ) and clinical remission (no onset of hypertension or no constitutional symptom). Although there was no further narrowing of left renal artery, contrast enhancement and edema of vascular wall that involved $8.5 \mathrm{~cm}$ segment in left renal artery were re-observed on control MR angiography (Figure 1). Because of clinical and laboratory remission with good physician's and patient's global assessment, CZP treatment was continued.

\section{DISCUSSION}

The major aim of treatment in TA is to prevent organ damage due to vasculitic process. Anti-TNF drugs are used in patients with active and refractory disease. ${ }^{19,20}$ There is no widely 


\begin{tabular}{|c|c|c|c|c|}
\hline Patients & $\begin{array}{c}\text { Type of Takayasu } \\
\text { arteritis }\end{array}$ & $\begin{array}{l}\text { Duration of CZP } \\
\text { treatment (months) }\end{array}$ & $\begin{array}{l}\text { Biologic DMARDs } \\
\text { prior to CZP }\end{array}$ & Efficacy of CZP \\
\hline 1 & III & 6 & No drug & Remission \\
\hline 2 & $\mathrm{~V}$ & 24 & IFX, TCZ & Remission \\
\hline 3 & V & 22 & No drug & Relapse \\
\hline 4 & I & 12 & No drug & Remission \\
\hline 5 & V & 24 & IFX & Remission \\
\hline 6 & V & 8 & IFX & Remission \\
\hline 7 & $\mathrm{~V}$ & 3 & IFX, TCZ & Remission \\
\hline 8 & V & 3 & $\mathrm{ADA}$ & Remission \\
\hline 9 & V & 8 & No drug & Remission \\
\hline 10 & $\mathrm{~V}$ & 28 & IFX, ADA, ETA & Remission \\
\hline \multicolumn{5}{|c|}{ Patients in our study } \\
\hline 1 & II & 26 & IFX, ETA & Remission \\
\hline 2 & II & 4 & No drug & Refractory \\
\hline 3 & V & 12 & No drug & Remission \\
\hline
\end{tabular}

accepted definition for refractory disease. The Turkish TA Study Group made a definition of refractory disease. ${ }^{6,21}$ According to the Turkish TA Study Group, refractory TA is defined as the presence of angiographic or clinical progression despite treatment or the presence of any of the following characteristics: (i) prednisolone dose $>7.5 \mathrm{mg} /$ day after six months of treatment, despite administration of conventional immunosuppressive agents, (ii) new surgery due to persistent disease activity, (iii) frequent attacks (more than three per year) or (iv) death associated with disease activity. CZP differs from other TNF inhibitors such as PEGylation and is free of a Fc region. These give advantages of a decreased transfer through the placenta and superior drug pharmacokinetics and bioavailability. ${ }^{15,22} \mathrm{CZP}$ has Food and Drug Administration approval for rheumatoid arthritis, ankylosing spondylitis, Crohn's disease, psoriatic arthritis, and plaque psoriasis. Although TNF inhibition was effective in most of the patients, there are no randomized controlled trials of TNF inhibitors in patients with TA. $8,23,24$ There are scarce data about CZP use in TA. In an abstract from 2018 ACR/ARHP Annual Meeting, it was reported that during follow-up, biologic agents were preferred for $13.8 \%$ of TA patients (5 infliximab and certolizumab each, 2 adalimumab, and 2 tocilizumab) and remission was observed in $84 \%$ of the patients. ${ }^{18}$ In the other brief report, the efficacy and safety of treatment with CZP in 10 female TA patients were evaluated. ${ }^{17}$ In this study, after CZP administration, all patients were able to taper prednisone and MTX doses. Remission was achieved in all patients at a median of four months. Relapse was observed only in one patient (Table 1). In our cases, CZP was ineffective in one of three patients.

Most TA patients are females and disease onset generally overlaps the reproductive age. High disease activity can result in pregnancy complications. Thus, effective and safe immunosuppression is required. When CZPexposed pregnancy outcomes were compared to normal population, no significant difference was observed. ${ }^{25}$ In another study, while concentrations of ADA and IFX were higher in infants at birth and their cords than in their mothers, concentration of CZP was lower. ${ }^{26}$

Although TNF inhibitors comprise an efficient therapy in TA, they also bring some challenges. Side effects (mainly infections and hypersensitivity reactions) are observed in $20 \%$ of cases. $^{27} \mathrm{~A}$ case of CZP-associated leukocytoclastic vasculitis was also reported. ${ }^{28}$ In another study evaluating TA patients treated with TNF inhibitors, 33\% of patients experienced disease relapse and 55\% discontinued treatment because of relapse, persistently active disease, 
lack of corticosteroid-sparing effect, adverse effects or other reasons. ${ }^{29}$ In our report, one out of the three patients was refractory to $\mathrm{CZP}$, in accordance with the literature. Since CZP is also a TNF inhibitor, it should be kept in mind that these side effects may be observed with use of CZP.

In our cases, CZP was effective in two patients in terms of laboratory and clinical remission and in one patient in terms of angiographic remission. One patient who benefited from CZP also had Crohn's disease in addition to TA and received multiple biologic and conventional disease modifying anti-rheumatic drugs.

In conclusion, CZP can be a treatment option in TA patients with concomitant inflammatory bowel disease or spondyloarthropathy, in patients unresponsive to other anti-TNF drugs or in young females with plans of pregnancy.

\section{Declaration of conflicting interests}

The authors declared no conflicts of interest with respect to the authorship and/or publication of this article.

\section{Funding}

The authors received no financial support for the research and/or authorship of this article.

\section{REFERENCES}

1. Jennette JC, Falk RJ, Bacon PA, Basu N, Cid MC, Ferrario F, et al. 2012 revised International Chapel Hill Consensus Conference Nomenclature of Vasculitides. Arthritis Rheum 2013;65:1-11.

2. Bicakcigil M, Aksu K, Kamali S, Ozbalkan Z, Ates A, Karadag $\mathrm{O}$, et al. Takayasu's arteritis in Turkey clinical and angiographic features of 248 patients. Clin Exp Rheumatol 2009;27:59-64.

3. Watts R, Al-Taiar A, Mooney J, Scott D, Macgregor A. The epidemiology of Takayasu arteritis in the UK. Rheumatology (Oxford) 2009;48:1008-11.

4. Arnaud L, Kahn JE, Girszyn N, Piette AM, Bletry O. Takayasu's arteritis: An update on physiopathology. Eur J Intern Med 2006;17:241-6.

5. Numano F, Kobayashi Y, Maruyama Y, Kakuta T, Miyata T, Kishi Y. Takayasu arteritis: clinical characteristics and the role of genetic factors in its pathogenesis. Vasc Med 1996;1:227-33.

6. Keser G, Aksu K, Direskeneli H. Takayasu arteritis: an update Turk J Med Sci 2018;48:681-97.

7. Arend WP, Michel BA, Bloch DA, Hunder GG,
Calabrese LH, Edworthy SM, et al. The American College of Rheumatology 1990 criteria for the classification of Takayasu arteritis. Arthritis Rheum 1990;33:1129-34.

8. Mekinian A, Comarmond C, Resche-Rigon M, Mirault T, Kahn JE, Lambert M, et al. Efficacy of Biological-Targeted Treatments in Takayasu Arteritis: Multicenter, Retrospective Study of 49 Patients. Circulation 2015;132:1693-700.

9. Pazzola G, Muratore F, Pipitone N, Crescentini F, Cacoub P, Boiardi L, et al. Rituximab therapy for Takayasu arteritis: a seven patients experience and a review of the literature. Rheumatology (Oxford) 2017 Jul 18.

10. Saadoun D, Lambert M, Mirault T, Resche-Rigon M, Koskas F, Cluzel P, et al. Retrospective analysis of surgery versus endovascular intervention in Takayasu arteritis: a multicenter experience. Circulation 2012;125:813-9.

11. Osman M, Aaron S, Noga M, Yacyshyn E. Takayasu's arteritis progression on anti-TNF biologics: a case series. Clin Rheumatol 2011;30:703-6.

12. Souabni L, Ben Abdelghani K, Jradi S, Zakraoui L. Takayasu's arteritis occurring under TNF- $\alpha$ blockers: a new paradoxical effect? BMJ Case Rep 2014;2014.

13. Mariani N, So A, Aubry-Rozier B. Two cases of Takayasu's arteritis occurring under anti-TNF therapy. Joint Bone Spine 2013;80:211-3.

14. Nesbitt A, Fossati G, Bergin M, Stephens P, Stephens S, Foulkes R, et al. Mechanism of action of certolizumab pegol (CDP870): in vitro comparison with other anti-tumor necrosis factor alpha agents. Inflamm Bowel Dis 2007;13:1323-32.

15. Mariette X, Förger F, Abraham B, Flynn AD, Moltó A, Flipo RM, et al. Lack of placental transfer of certolizumab pegol during pregnancy: results from CRIB, a prospective, postmarketing, pharmacokinetic study. Ann Rheum Dis 2018;77:228-233.

16. Kerr GS, Hallahan CW, Giordano J, Leavitt RY, Fauci AS, Rottem M, et al. Takayasu arteritis. Ann Intern Med 1994;120:919-29.

17. Novikov PI, Smitienko IO, Sokolova MV, AlibazOner F, Kaymaz-Tahra S, Direskeneli $\mathrm{H}$, et al. Certolizumab pegol in the treatment of Takayasu arteritis. Rheumatology (Oxford) 2018;57:2101-5.

18. Kaymaz Tahra S, Alibaz-Oner F, Direskeneli H. Long term follow-up results of takayasu arteritis cohort: a tertiary-single center study. Arthritis Rheumatol 2018;70(Suppl 10). Available from: https:// acrabstracts.org/abstract/long-term-follow-up-resultsof-takayasu-arteritis-cohort-a-tertiary-single-centerstudy/ [Accessed: September 19, 2018].

19. Freitas DS, Camargo CZ, Mariz HA, Arraes AE, de Souza AW. Takayasu arteritis: assessment of response to medical therapy based on clinical activity criteria and imaging techniques. Rheumatol Int 2012;32:703-9. 
20. Arnaud L, Haroche J, Limal N, Toledano D, Gambotti L, Costedoat Chalumeau N, et al. Takayasu arteritis in France: a single-center retrospective study of 82 cases comparing white, North African, and black patients. Medicine (Baltimore) 2010;89:1-17.

21. Saruhan-Direskeneli G, Hughes T, Aksu K, Keser G, Coit P, Aydin SZ, et al. Identification of multiple genetic susceptibility loci in Takayasu arteritis. Am J Hum Genet 2013;93:298-305.

22. Chapman AP. PEGylated antibodies and antibody fragments for improved therapy: a review. Adv Drug Deliv Rev 2002;54:531-45.

23. Novikov PI, Smitienko IO, Moiseev SV. Tumor necrosis factor alpha inhibitors in patients with Takayasu's arteritis refractory to standard immunosuppressive treatment: cases series and review of the literature. Clin Rheumatol 2013;32:1827-32.

24. Nakagomi D, Jayne D. Outcome assessment in Takayasu arteritis. Rheumatology (Oxford) 2016;55:1159-71.

25. Clowse MEB, Scheuerle AE, Chambers C, Afzali A, Kimball AB, Cush JJ, et al. Pregnancy Outcomes
After Exposure to Certolizumab Pegol: Updated Results From a Pharmacovigilance Safety Database. Arthritis Rheumatol 2018;70:1399-407.

26. Mahadevan U, Wolf DC, Dubinsky M, Cortot A, Lee SD, Siegel CA, et al. Placental transfer of antitumor necrosis factor agents in pregnant patients with inflammatory bowel disease. Clin Gastroenterol Hepatol 2013;11:286-92.

27. Comarmond C, Plaisier E, Dahan K, Mirault T, Emmerich J, Amoura Z, et al. Anti TNF- $\alpha$ in refractory Takayasu's arteritis: cases series and review of the literature. Autoimmun Rev 2012;11:678-84.

28. Woody M, Warren D, Speck L, Jackson J. Leukocytoclastic vasculitis drug reaction to certolizumab pegol. Proc (Bayl Univ Med Cent) 2017;30:213-4.

29. Schmidt J, Kermani TA, Bacani AK, Crowson CS, Matteson EL, Warrington KJ. Tumor necrosis factor inhibitors in patients with Takayasu arteritis: experience from a referral center with long-term followup. Arthritis Care Res (Hoboken) 2012;64:1079-83. 